\title{
Evidence-Based Management: An Overview
}

\author{
Zohreh Sohrabi ${ }^{1}$, Nazila Zarghi2,3* \\ ${ }^{1}$ Department of Medical Education, Iran University of Medical Sciences (IUMS), Tehran, Iran \\ ${ }^{2}$ Medical Education, Tehran University of Medical Sciences (TUMS), Tehran, Iran \\ ${ }^{3}$ Education Development Center (EDC), Mashhad University of Medical Sciences (MUMS), Mashhad, Iran \\ Email: zarghin@mums.ac.ir
}

Received 18 August 2015; accepted 18 September 2015; published 21 September 2015

Copyright (C) 2015 by authors and Scientific Research Publishing Inc.

This work is licensed under the Creative Commons Attribution International License (CC BY).

http://creativecommons.org/licenses/by/4.0/

(c) (i) Open Access

\begin{abstract}
Evidence-based management is not a new idea. It has developed several years ago, however, it continued through the movement of evidence-based practice following emerging well-known definition of David Sackett from evidence-based medicine. As other professionals, the movement of evidence-based practice, as well as its application in real setting faces to many challenges. This study aimed to address Evidence-based management definition, principles and its challenges for applying in real settings and the possible solutions to overcome the barriers.
\end{abstract}

\section{Keywords}

\section{Evidence, Evidence-Based Management, Evidence-Based Practice}

\section{Introduction}

Evidence-based management has been influenced by evidence-based paradigm, however, the nature of evidence and its application may differ from the most well-known evidence-based practice, evidence-based medicine. While practitioners practice just as around $13 \%$ in their clinical setting, where everything is objective, managers also try to follow evidence-based management in their complex setting with higher level of subjectivity. Apart from different nature of evidence and complexity of evidence application in different organizations especially health care organizations, they meet different barriers to be overcome. The present study presents a literature review on the definition, principles and barriers of evidence-based management and how to overcome those barriers.

\section{Evidence-Based Practice Definition}

There are several definitions for evidence-based practice, but the most frequently and used one is definition of

"Corresponding author. 
David Sackett from evidence-based medicine. As many professions have under influenced by advantages of an evidence-based approach to practice and learning; so, since 2005, the concept of evidence-based medicine was became wider in 2005 to "evidence-based practice" in order to concentrate on more sharing evidence-based practitioners attitude towards evidence-based practice paradigm. Sicily statement of evidence-based practice has presented the following definition. Although it does not provide a clear statement of what evidence-based practice means, it mentions the minimum necessary skill in order to practice in an evidence-based way.

"Evidence-based practice is about making decisions through the conscientious, explicit and judicious use of the best available evidence from multiple sources by:

$\begin{array}{ll}\text { 1. Asking: } & \text { translating a practical issue or problem into an answerable question } \\ \text { 2. Acquiring: } & \text { systematically searching for and retrieving the evidence } \\ \text { 3. Appraising: } & \text { critically judging the trustworthiness and relevance of the evidence } \\ \text { 4. Aggregating: } & \text { weighing and pulling together the evidence } \\ \text { 5. Applying: } & \text { incorporating the evidence in the decision-making process } \\ \text { 6. Assessing: } & \text { evaluating the outcome of the decision taken } \\ \text { To increase the likelihood of a favorable outcome" (http://www.cebma.org/a-definition-of-evidence-based-management/). }\end{array}$

\section{Evidence-Based Management}

Evidence-based management is not a new idea. Chester Barnard (1938) primarily developed a natural science of organization in order to better understanding either unexpected or unpredicted problems related to authority and consent (Barnard, 1983). Evidence-based management, provides a model to guide how to bridge research-practice gap in field of management (Rousseau, 2006).

According to Merriam-Webster dictionary, management has been defined as "a judicious use of means to accomplish an end" (Webster, 2005). Evidence-based management means translating principles based on best evidence into organizational practices. Through evidence-based management, managers could make their organizational decisions assisted by social science and organizational research in which they move away from personal preference and unsystematic experience toward decisions based on the best available scientific evidence (De Angelis, 2005; Lemieux-Charles \& Champagne, 2004; Rousseau, 2005; Walsh \& Rundall, 2001). Therefore managers would be able to make decisions continually research based, according to principles underlying human behavior and organizational actions, i.e. they got principles from research evidence and translates them into practices in order to solve their organizational problems. This is not always easy. Because, principles are credible just when the evidence is crystal clear, and findings could be interpreted by researchers and practitioners in a similar way.

Despite the challenges, evidence-based management has potential for achieving organizational goals, associated with employees, stockholders, and the public in general. Rousseau (2006) stated that "Out of these personal and professional experiences, I have nurtured my great hope- that, through research and education, we can promote effective organizations where managers make well-informed, less arbitrary and more reflective decisions. My great disappointment, however, has been that research findings don’t appear to have transferred well to the workplace. Instead of a scientific understanding of human behavior and organizations, managers, including those with MBAs, continue to rely largely on personal experience, to the exclusion of more systematic knowledge” (Rousseau, 2006).

\section{Principles of Evidence-Based Management}

The framework of Evidence-based management is depending on the following principles:

1. Face the hard facts, and build a culture in which people are encouraged to tell the truth, even if it is unpleasant.

2. Be committed to "fact based" decision making — which means being committed to getting the best evidence and using it to guide actions.

3. Treat your organization as an unfinished prototype —encourage experimentation and learning by doing.

4. Look for the risks and drawbacks in what people recommend — even the best medicine has side effects.

5. Avoid basing decisions on untested but strongly held beliefs, what you have done in the past, or on uncritical "benchmarking" of what winners do (http://evidence-basedmanagement.com/)

Evidence-based practice plays the role of paradigm for making decisions integrated with best available re- 
search evidence by which decision maker prefers to guide his practice toward more desirable results (Sackett, Straus, Richardson, Rosenberg, \& Haynes, 2000). Evidence-based practice advocators are doubtful about applying experience, wisdom, or personal credentials in their workplace. So, firstly, the question is what is the evidence? Not "Who says so?” (Sherman, 2002). An evidence orientation shows that decision quality is more based on a function of available facts, for providing reliable and valid information when making managerial and organizational decisions. This trend continues recently as open-book management (Case, 1995, Ferrante \& Rouseeau, 2001) i.e. decision quality is directly under influence of available facts rather than research findings (Pfeffer \& Sutton, 2006). Therefore, let's differentiate what might be called "Big E Evidence" from "little e evidence.” When you apply Big E Evidence, you apply generalizable knowledge derived from scientific methods, but little e evidence is local or organization specific (Deming, 1993, Evans \& Dean, 2000). It refers to systematically data collection in a particular setting to inform local decisions. So, "facts are our friends," when we would like to gather relevant data for a particular problem and decide to lead more effective solutions. Although decision makers who rely on scientific principles are more likely to gather facts systematically in order to choose an appropriate course of action (Sackett, Straus, Richardson, Rosenberg, \& Haynes, 2000), fact gathering ("evidence") does not necessarily lead decision makers to use social science knowledge ("Evidence") in interpretating these facts. It is recommended to follow six-step approach as evidence-informed approach to decision making as follows:

\section{Framing the management question.}

2. Finding sources of information.

3. Assessing the accuracy of the information.

4. Assessing the applicability of the information.

5. Assessing the action ability of the evidence.

6. Determining if the information is adequate (Rundall, Martelli, Arroyo, \& Mc Curdy, 2007).

However, more than scientific insight is needed to perform evidence-based practice. Organizational factors affect on occurrence evidence-based practice as well as social networks and organizational culture. It is also important that decision supports should make easier implementation of evidence-based practices. Finally, several factors such as individual (knowledge), organizational (access to knowledgeable others, support for evidence use), and institutional (dissemination of evidence-based practice) should be regarded for promoting, sustaining and industrializing evidence-based practice in an organization (Rousseau, 2006).

\section{Evidence-Based Management Barriers}

Evidence based practice frequently has been misapplied. It can be used as either superficial practices or as a club to force compliance with a standard that may not be internationally applied. Evidence-based practice is not one size-fits-all; it's the best available evidence integrated with informed expert judgment. However, still implementation evidence-based management is a strong suit through the available research findings to guide goal setting and feedback (Locke \& Latham, 1984), feedback and redesign (Goodman \& Rousseau, 2004) in the real settings.

As there is not yet any empirical research demonstrated the effectiveness of evidence-based management, it is based mostly on conceptual arguments. Research is needed into the diffusion of evidence-based management in health care organizations as well as into the results achieved by organizations that used the practice compared with organizations that did not.

Managers should use available data when planning and implementing decisions. On the other hand, evidence from research should play a role in all execution affairs of organizations (Arndt \& Bigelow, 2009).

Managers face to numerous barriers such as time pressures, perceived threats to autonomy, preference for colloquial knowledge based on individual experiences, difficulty accessing the relevant evidence base, reliance on external consultants for determining quality of data, and lack of resources (Rundall, Martelli, Arroyo, \& MCurdy, 2007).

The research-practice gap among managers is a multi factorial situation. The most important one is, that managers do not know the evidence. Despite the explosion of research on decision making, management, and other domains directly tied to organizational practices, few practicing managers access this work. Evidencebased management can threaten managers' personal autonomy for their decision-making in organizations.

The other barrier is associated with this belief that good management is an art—-the "romance of leadership" 
school of thought (Meindle, Erlich, \& Dukerich, 1985), in which using evidence is equal to loss of creativity and autonomy (Parker, 2005). On the other hand, managerial decisions often take long time with little feedback; they often are under influence of stakeholders (Miller, 1992); it should be noted that mostly decisions are made based on interactions that compose managerial work (Walshe \& Rundall, 2001).

Another problem is the diverse backgrounds and education of managers. With no formally education or credentials, practicing managers have no body of shared knowledge. Lacking shared scientific knowledge to add weight to an evidence-based decision, managers commonly rely on their experience, formal power, incentives, and threats when making decisions (Cyert \& Goodman, 1997).

In contrast to more evidence-oriented domains, such as policing and education, management is most often a private sector activity. It is less influenced by public policy pressures promoting similar practices while creating comparative advantage via distinctiveness.

No communities of experts vet research regarding effective management practice. Consequently, it's time to look critically at the role we educators play in limiting managers' knowledge and use of research evidence.

\section{How to Overcome?}

Managers need real learning. Today, the poor information are available to managers in terms of consequences of their decisions for their organization. The reality is that managers tend to work in settings that make valid learning difficult (Walshe \& Randall, 2001; Staw \& Epstein, 2000). In such settings managers cannot even learn why their decisions were wrong, let alone what alternatives would have been right. Evidence-based management leads to valid learning and continuous improvement. Organizational legitimacy is another product of evidencebased management. Legitimacy is a result of making decisions in a systematic and informed fashion, thus making a firm's actions more readily justifiable in the eyes of stakeholders.

Management education is itself often not evidence based, something Trank and Rynes implicitly recognize (2003) as the "dumbing down" of management education. Stimulating courses and active learning must be core features of training in evidence-based management, because these educational features are good pedagogy. The manner and content of our approaches to behavioral courses perpetuate the research-practice gap (Ryne, Trank, Lawson, \& Ilies, 2003). Professors are likely to teach what they learned in graduate school and not necessarily what current research supports (Since many management professors are adjuncts valued for their practical experience but are from diverse backgrounds, even educators of comparable professional age may not share scientific knowledge).

According to Rousseau (2005) for evidence-based management practice development, the followings have been recommended:

- "Learning about cause-effect connections in professional practices.

- Isolating the variations that measurably affect desired outcomes.

- Creating a culture of evidence-based decision making and research participation.

- Using information-sharing communities to reduce overuse, underuse, and misuse of specific practices.

- Building decision supports to promote practices the evidence validates, along with techniques and artifacts that make the decision easier to execute or perform (e.g., checklists, protocols, or standing orders).

- Having individual, organizational, and institutional factors promote access to knowledge and its use".

The other solutions for promoting could be summarized in firstly, managing expectations of students in order to face them in their future jobs, managerial roles (Ryne, Trank, Lawson, \& Ilies, 2003); secondly, providing models of Evidence-Based Practice for active practice, self-reflection, and feedback are core learning principles (Schön, 1983). Similarly, planning educational practices, courses, and curricula for reflection and evolution evidence based teaching; thirdly, promoting active use of evidence, in which participants learn how to find and apply evidence (Bennis \& O’Toole, 2004). Actually using evidence is a meta skill, a procedural knowledge for effectively translating the evidence into guides for action (Mohrman \& Mohrman 1997); finally, building collaborations among managers, researchers, and educators (Gladwell, 2002), networks of individuals, excited by what evidence-based management makes possible, need to exist to disseminate it to others (Kovner, Elton, \& Billings, 2005).

\section{Conclusion}

Although evidence-based management will offer a model for practice, it is strongly recommended to provide 
atmosphere for learning and reflection supported by giving feedback in real settings. On the other hand, building collaboration among managers, researchers, and educators could facilitate evidence-based management application movement as well.

\section{References}

Arndt, M., \& Bigelow, B. (2009). Evidence-Based Management in Health Care Organizations: A Cautionary Note. Health Care Management Review, 34, 206-213. http://dx.doi.org/10.1097/HMR.0b013e3181a94288

Barnard, C. I. (1938). Functions of the Executive. Cambridge, MA: Harvard University Press.

Bennis, W. G., \& O’Toole, J. (2004). How Business Schools Lost Their Way. Harvard Business Review, 82, 96-104.

Case, J. (1995). Open-Book Management: The Coming Business Revolution. New York: Harper Business.

Cyert, R. M., \& Goodman, P. S. (1997). Creating Effective University-Industry Alliances: An Organizational Learning Perspective. Organizational Dynamics, 25, 45-57. http://dx.doi.org/10.1016/S0090-2616(97)90036-X

De Angelis, T. (2005). Shaping Evidence-Based Practice. APA Monitor, 35, $26-31$.

Deming, W. E. (1993). The New Economics for Industry, Government, and Education. Cambridge, MA: Massachusetts Institute of Technology.

Evans, J. R., \& Dean Jr., J. W. (2000). Total Quality: Management, Organization, and Strategy (2nd ed.). Cincinnati: South-Western Publishing.

Ferrante, C. J., \& Rousseau, D. M. (2001). Bringing Open Book Management into the Academic Line of Sight. In C. L. Cooper, \& D. M. Rousseau (Eds.), Employee versus Owner Issues (Trends in Organizational Behavior Series) (pp. 97116). Chichester: Wiley.

Gladwell, M. (2002). The Tipping Point: How Little Things Can Make a Big Difference. New York: Back Bay Books.

Goodman, P. S., \& Rousseau, D. M. (2004). Organizational Change That Produces Results. Academy of Management Executive, 18, 7-19. http://dx.doi.org/10.5465/AME.2004.14776160

http://evidence-basedmanagement.com/

http://www.cebma.org/a-definition-of-evidence-based-management/

Kovner, A. R., Elton, J. J., \& Billings, J. D. (2005). Evidence-Based Management. Frontiers of Health Services Management, 16, 3-24.

Lemieux-Charles, L., \& Champagne, F. (2004). Using Knowledge and Evidence in Healthcare: Multidisciplinary Perspectives. Toronto: University of Toronto Press.

Locke, E. A., \& Latham, G. P. (1984). Goal Setting: A Motivational Technique That Works. Englewood Cliffs, NJ: Prentice Hall.

Meindle, J. R., Erlich, S. B., \& Dukerich, J. M. (1985). The Romance of Leadership. Administrative Science Quarterly, 30, 78-101. http://dx.doi.org/10.2307/2392813

Miller, G. J. (1992). Managerial Dilemmas: The Political Economy of Hierarchy. Cambridge: Cambridge University Press. http://dx.doi.org/10.1017/CBO9781139173742

Mohrman, S. A., \& Mohrman Jr., A. M. (1997). Designing and Leading Team-Based Organizations: A Workbook for Organizational Self-Design. San Francisco, CA: Jossey-Bass.

Parker, M. (2005). False Dichotomies, EBM, Clinical Freedom and the Art of Medicine. Medical Humanities, 31, $23-30$. http://dx.doi.org/10.1136/jmh.2004.000195

Pfeffer, J., \& Sutton, R. I. (2006). Hard Facts, Dangerous Half-Truths, and Total Nonsense: Profiting from Evidence-Based Management. Boston, MA: Harvard Business School Press.

Rousseau, D. M. (2005). Evidence-Based Management in Health Care. In C. Korunka, \& P. Hoffmann (Eds.), Change and Quality in Human Service Work (pp. 33-46). Munich: Hampp.

Rousseau, D. M. (2006). Is There Such a Thing as “Evidence-Based Management”? Academy of Management Review, 31, 256-269. http://dx.doi.org/10.5465/AMR.2006.20208679

Rundall, T. G., Martelli, P. F., Arroyo, L., \& McCurdy, R. (2007). The Informed Decisions Toolbox: Tools for Knowledge Transfer and Performance Improvement/Practitioner Application. Journal of Healthcare Management, 52, 325-341.

Rynes, S. L., Trank, C. Q., Lawson, A. M., \& Ilies, R. (2003). Behavioral Coursework in Business Education: Growing Evidence of a Legitimacy Crisis. Academy of Management Learning \& Education, 2, 269-283.

http://dx.doi.org/10.5465/AMLE.2003.10932135

Sackett, D. L., Straus, S. E., Richardson, W. S., Rosenberg, W., \& Haynes, R. B. (2000). Evidence-Based Medicine: How to 
Practice and Teach EBM. New York: Churchill Livingstone.

Schön, D. (1983). The Reflective Practitioner: How Professionals Think in Action. London: Temple Smith.

Sherman, L. W. (2002). Evidence-Based Policing: Social Organization of Information for Social Control. In E. Waring, \& D. Weisburd (Eds.), Crime and Social Organization (pp. 217-248). New Brunswick, NJ: Transaction.

Staw, B., \& Epstein, L. (2000). What Bandwagons Bring: Effects of Popular Management Techniques on Corporate Performance, Reputation, and CEO Pay. Administrative Science Quarterly, 43, 523-556. http://dx.doi.org/10.2307/2667108

Walshe, K., \& Rundall, T. G. (2001). Evidence-Based Management: From Theory to Practice in Health Care. Milbank Quarterly, 79, 429-457. http://dx.doi.org/10.1111/1468-0009.00214

Webster, M. (2005). Online Dictionary. 